\title{
APLICAÇÃO DO PROCESSO DE SEPARAÇÃO POR MEMBRANA PARA PRODUÇÃO DE CHÁ VERDE CLARIFICADO E CONCENTRADO
}

\author{
L. S. SOUSA ${ }^{1 *}$,T. S. CARMO ${ }^{1}$, T. M. A. PINHEIRO ${ }^{1}$, L. N FALLEIROS ${ }^{1}$ V. L. CARDOSO ${ }^{1}$, M. \\ H. M. REIS ${ }^{1}$ \\ ${ }^{1}$ Universidade Federal de Uberlândia, Departamento de Engenharia Química \\ e-mail: sousa.larissa@yahoo.com.br
}

\begin{abstract}
RESUMO
Os bioativos presentes no chá verde são muito estudados por apresentarem propriedades antioxidandes que são capazes de prevenir algumas doenças. Além desses compostos, conhecidos como catequinas, existem outros compostos como proteínas, aminoácidos e açúcares que são responsáveis pelo aroma e pelas características do chá verde. A remoção desses sólidos que se encontram solubilizados, é de grande importância para garantir a estabilidade do chá verde que será ingerido. Com o intuito de concentrar e extrair as catequinas, faz-se necessário utilizar algum processo de separação. Dessa forma, o objetivo deste trabalho é avaliar o processo de separação por membranas para clarificar (reduzir os sólidos solúveis) e concentrar (as catequinas) o chá verde. Foram avaliadas diferentes temperaturas de infusão para extração das catequinas e os resultados mostraram que na temperatura de $75^{\circ} \mathrm{C}$ foi obtida a maior concentração, que foi de $1612,80 \mathrm{mg} / \mathrm{L}$. Das três membranas utilizadas no processo de microfiltração, aquela que se mostrou mais eficiente foi a de porosidade igual a $0,22 \mu \mathrm{m}$ uma vez que no permeado houve uma concentração das catequinas de $80,70 \%$ e redução dos sólidos totais de $20,95 \%$. Desta forma, tem-se que o processo de separação por membranas é eficiente na clarificação e concentração do chá verde.
\end{abstract}

\section{INTRODUÇÃO}

O chá, incluindo o verde, o preto e o branco, é a segunda bebida mais consumida em todo o mundo, perdendo apenas para a água (LEE et al., 2015). O chá verde, é mundialmente conhecido pelas suas propriedades antioxidantes que ajudam a inibir os radicais livres protegendo $o$ organismo humano de algumas doenças (NAGAO, HASE, TOKIMITSU, 2007).

As catequinas são as responsáveis por proporcionar este efeito antioxidante do chá verde, mas além delas existem muitos tipos de compostos solúveis indispensáveis para o aroma e sabor do chá, incluindo flavonóis, proteínas aminoácidos, açúcares, polissacáridos, lipídios, cafeína, minerais, dentre outros (JIANG et al., 2015).

A remoção dos sólidos solúveis presentes no chá verde é um importante passo para garantir a estabilidade do chá que será ingerido. Métodos convencionais de remoção como a clarificação por centrifugação/filtração, seguida de ajustes na temperatura e do uso de substâncias químicas como enzimas, aumentam a solubilidade desses sólidos. Empregando esta técnica de separação, a parte sensorial e nutricional da bebida é comprometida. O uso de membranas 
pode superar essas desvantagens e por causa disso, esta técnica é amplamente aplicada para a clarificação de sucos de frutas (CHANDINI, RAO, SUBRAMANIAN, 2013).

Um dos métodos mais convencionais de extração das catequinas do chá verde, é a extração por solventes como metanol e etanol e a adsorção é utilizada como processo de separação. A proposta de utilizar membranas para o processo de separação se mostra bastante atrativa, já que esta tecnologia se mostra muito eficiente no processo de clarificação de vários sucos de frutas (KUMAR, THAKUR, DE 2012). O processo de filtração utilizando membranas, além de reter materiais particulados e coloidais, podem incluir também constituintes dissolvidos dependendo da porosidade da membrana (BARBOSA, 2009). Os processos de separação com membrana, como a microfiltração e a ultrafiltração, são utilizados como métodos alternativos de conservação de bebidas. Nestes processos, não ocorre mudança de fase e não é utilizada nenhuma fonte de calor, dessa forma as características sensoriais e nutricionais dos produtos são mantidas (CARNEIRO et al., 2000).

A clarificação do extrato do chá verde é necessária para reduzir sedimentos e é considerado um processo eficiente para o processo de concentração (KAWAKATSU et al., 1995).

A microfiltração (MF) é o processo de separação com membranas mais próximo da filtração clássica. $\mathrm{O}$ diâmetro dos poros dessas membranas está na faixa de 0,1 e 10 $\mu \mathrm{m}$. Como elas são relativamente abertas, as pressões empregadas são pequenas, não costuma passar de 1 bar (HABERT, 2006).

Este trabalho tem como objetivo, clarificar o chá verde e concentrar as catequinas presentes no mesmo utilizando membranas de microfiltração.

\section{MATERIAIS E MÉTODOS}

\subsection{Materiais utilizados}

Todos os solventes e reagentes que foram usados eram analiticamente puros. $\mathrm{O}$ reagente Folin-Ciocalteu foi adquirido da Merck, o ácido gálico, e o carbonato de sódio $\left(\mathrm{Na}_{2} \mathrm{CO}_{3}\right)$ da Vetec. As medidas de absorção foram feitas no espectrofotômetro UVmini 1240 Shimadzu. As folhas já processadas do chá verde foram adquiridas em um estabelecimento comercial da cidade de Uberlândia (MG). As membranas utilizadas na microfiltração foram planas de éster de celulose, uma com $0,8 \mu \mathrm{m}$, outras com $0,3 \mu \mathrm{m}$ outra com $0,22 \mu \mathrm{m}$ de diâmetro de poro, ambas com $90 \mathrm{~mm}$ de diâmetro, da marca Milipore. Para os processos de filtração foi usado um sistema tipo batelada conectado a um cilindro de nitrogênio como mostrado na figura 1. $\mathrm{O}$ cilindro de nitrogênio foi adquirido da White Martins. A estufa usada é da Med Clave modelo 4.

\subsection{Preparação da amostra}

Testes foram realizados para encontrar a temperatura e tempo de infusão ideal para extração das catequinas. Basicamente foram pesados $100 \mathrm{~g}$ de folhas de chá verde para 1 litro de água, essa mistura foi colocada em banho térmico e de tempos em tempos amostras eram coletadas para medir a concentração de catequinas. Quando estas passaram a ser constantes, a infusão foi encerrada.

\subsection{Determinação das catequinas totais}

A determinação do teor de catequinas totais presentes no chá verde foi feita por meio da metodologia usada por KUMAR, THAKUR, DE (2012), ou seja, espectroscopia na região do visível utilizando o método de Folin-Ciocalteu.

A curva de calibração foi construída com dez concentrações conhecidas de ácido gálico variando de $0,4 \mathrm{mg} / \mathrm{L} \mathrm{a} \mathrm{4,0} \mathrm{mg/L.}$ 
Para medidas do teor de catequinas no chá verde tomou-se uma amostra de $0,05 \mathrm{ml}$ que foi adicionado em um béquer. Neste béquer, $0,2 \mathrm{ml}$ da solução de Folin-Ciocalteu foi adicionada, depois de passados dois minutos, $2 \mathrm{~mL}$ da solução de $\mathrm{Na}_{2} \mathrm{CO}_{3}$ a $10 \%$ foi adicionada. A adição dessa solução de $\mathrm{Na}_{2} \mathrm{CO}_{3}$ foi considerada o tempo zero. $\mathrm{O}$ volume total da solução foi ajustado para 4 mL usando água destilada. Após uma hora, os valores de absorbância foram medidos a uma frequência de $760 \mathrm{~nm}$ usando o espectofotômetro UVmini - 1240 Shimadzu.

\subsection{Determinação dos sólidos totais}

A redução dos sólidos totais presentes no chá verde foi determinada através da Equação 1. Para calcular a concentração de sólidos após a infusão e após a microfiltração, as Equações 2 e 3 foram utilizadas. Para isso, uma amostra de $0,005 \mathrm{~L}$ foi coletada de cada etapa, as mesmas foram colocadas na estufa por $24 \mathrm{~h}$ a uma temperatura de $100^{\circ} \mathrm{C}$ e após esse tempo foi aferida a massa final para cada amostra.

Redução dos sólidos totais (\%) =

$\left(1-\frac{\text { Concentração de sólidos após a microfiltração }(\mathrm{mg} / \mathrm{L})}{\text { Concentração de sólidos após a infusão }(\mathrm{mg} / \mathrm{L})}\right) * 100$

Concentração de sólidos após a microfiltração = Massa de sólidos após a microfiltração $(\mathrm{mg})$ Volume da amostra (L)

Concentração de sólidos após a infusão = Massa de sólidos após a infusão $(\mathrm{mg})$

Volume da amostra $(L)$

Volume da amostra $=0,005 \mathrm{~L}$

\subsection{O processo de microfiltração}

A solução de chá verde recém preparada, foi microfiltrada em três membranas de éster de celulose de porosidade diferente, a primeira com porosidade $0,8 \mu \mathrm{m}$, a segunda com porosidade $0,3 \mu \mathrm{m}$ e a terceira com porosidade $0,22 \mu \mathrm{m}$ durante 60 minutos, a uma pressão de 0,7 bar. Como a capacidade total do vaso para a filtração era de $500 \mathrm{ml}$, um volume inicial de chá verde de $300 \mathrm{ml}$ foi utilizado em cada experimento. A pressão de operação foi monitorada utilizando o manômetro mostrado na Figura 1, e a válvula contida neste mesmo manômetro foi utilizada para controlar a pressão dentro do módulo.

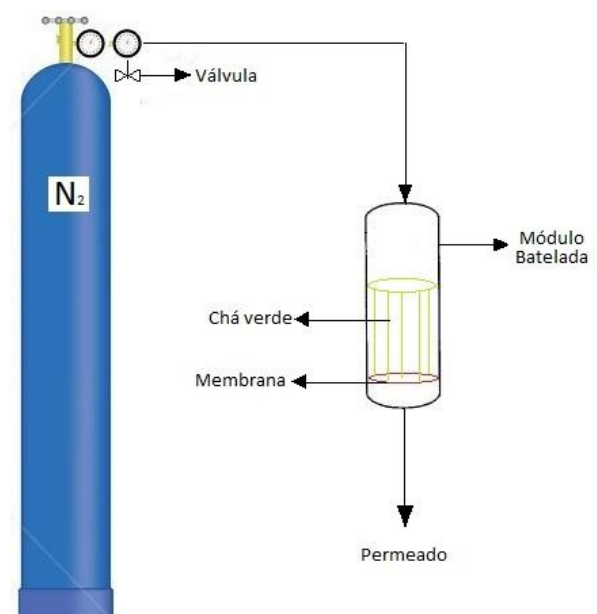

Figura 1 - Esquema Utilizado para o Processo de Microfiltração

\section{RESULTADOS E DISCUSSÕES}

A curva de calibração obtida para calcular as catequinas totais existentes em cada amostra analisada, apresentou a seguinte equação de reta y $=0,0051 x$ em que y é a concentração de ácido gálico e $x$ é a absorbância, com coeficiente de correlação 0,998 .

Para se verificar o efeito da temperatura de infusão sobre a concentração das catequinas totais, testes foram realizados em diferentes temperaturas que variaram de $45^{\circ} \mathrm{C}$ a $80^{\circ} \mathrm{C}$. Como pode ser observada na Figura 2 , a concentração de catequinas aumentou com o aumento da temperatura até $75^{\circ} \mathrm{C}$. Ao atingir $80^{\circ} \mathrm{C}$ observa-se um decaimento de $23,13 \%$ na concentração de catequinas totais. De acordo com TEREFE, et al., (2015) as catequinas começam a se decompor em temperaturas iguais ou superiores a $80^{\circ} \mathrm{C}$, por isso foi detectado este decaimento e dessa forma, a temperatura de infusão escolhida foi 
a de $75^{\circ} \mathrm{C}$. O tempo de infusão das folhas de chá verde utilizado durante o experimento foi de 60 minutos, pois é a partir deste tempo que se observa uma constância na concentração das catequinas.

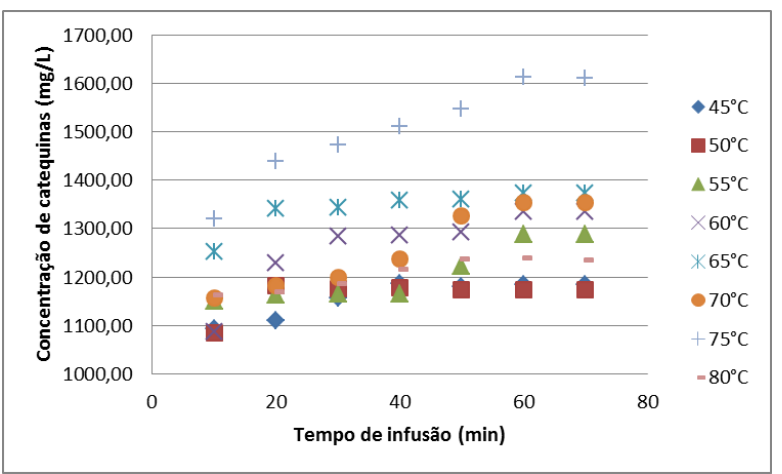

Figura 2 - Concentração de Catequinas Totais em Função do Tempo de Infusão das Folhas de Chá Verde para Diferentes Temperaturas

Com o objetivo de medir a eficiência de separação do processo de microfiltração utilizando três membranas de porosidade diferente, uma solução estoque de chá verde foi dividida em três partes iguais e as mesmas foram utilizadas nos processos de microfiltração. As propriedades do chá verde recém preparado e dos permeados de cada microfiltração podem ser observados na Tabela 1 e na Tabela 2. O comportamento do fluxo do permeado para cada membrana, pode ser observado na Figura 3.

Tabela 1 - Propriedades do Chá Verde Recém Preparado

\begin{tabular}{ccc}
\hline Solução & $\begin{array}{c}\text { Concentração } \\
\text { de fenólicos } \\
(\mathrm{mg} / \mathrm{L})\end{array}$ & $\begin{array}{c}\text { Sólidos totais } \\
(\mathrm{mg})\end{array}$ \\
\hline Chá verde & 1116,29 & 123,6 \\
\hline
\end{tabular}

Tabela 2 - Propriedades dos Permeados de Cada Microfiltração

\begin{tabular}{ccc}
\hline $\begin{array}{c}\text { Porosidade } \\
\text { da } \\
\begin{array}{c}\text { membrana } \\
(\mu \mathrm{m})\end{array}\end{array}$ & $\begin{array}{c}\text { Concentração } \\
\text { de fenólicos } \\
(\mathrm{mg} / \mathrm{L})\end{array}$ & $\begin{array}{c}\text { Sólidos totais } \\
(\mathrm{mg})\end{array}$ \\
\hline $0,8 \mu \mathrm{m}$ & 1025,71 & 122,6 \\
$0,3 \mu \mathrm{m}$ & 935,14 & 109,5 \\
$0,22 \mu \mathrm{m}$ & 900,86 & 97,7 \\
\hline
\end{tabular}

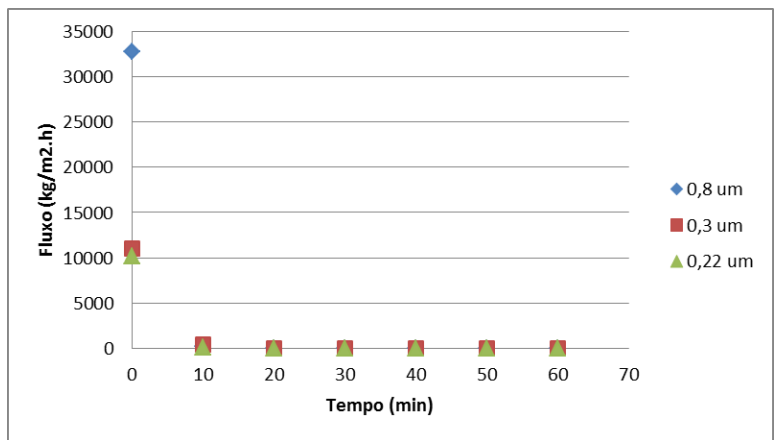

Figura 3 - Comportamento do Fluxo do Permeado para Cada Membrana Utilizada no Processo de Microfiltração

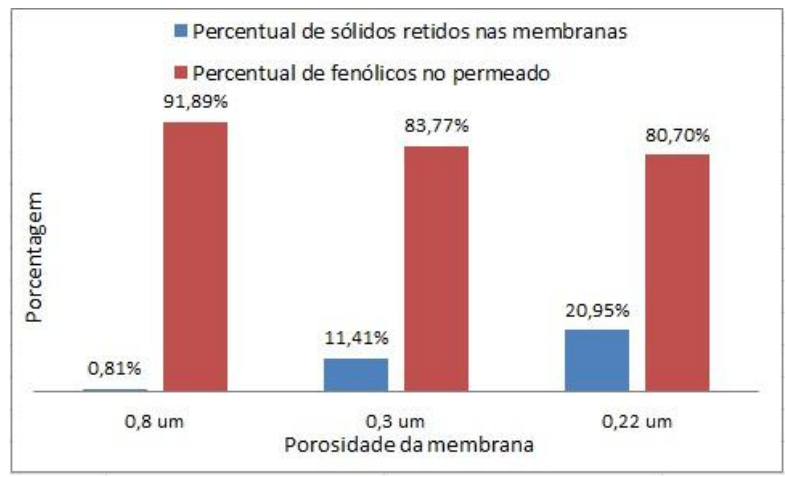

Figura 4 - Porcentagem de Retenção dos Sólidos Totais Presentes no Chá Verde e Porcentagem de Fenólicos no Permeado para Cada Membrana Utilizada no Processo de Microfiltração

Pela Figura 3 observa-se que o maior fluxo inicial, de 32783,05 $\left(\mathrm{kg} / \mathrm{m}^{2} \mathrm{~h}\right)$, está relacionado com a membrana de porosidade igual a $0,8 \mu \mathrm{m}$, para as membranas de porosidade $0,3 \mu \mathrm{m}$ e $0,22 \mu \mathrm{m}$, o fluxo inicial foi de, 10997,58 (kg/ m² h) e 10226,21 $(\mathrm{kg} /$ $\mathrm{m}^{2} \mathrm{~h}$ ) respectivamente. A diferença entre os fluxos destas duas últimas membranas não é 
tão pronunciada, pois a diferença entre o tamanho dos poros é pequena. Observa-se também, que após 10 minutos de operação o fluxo passa a ser constante e apresenta praticamente o mesmo valor para as três membranas. Apesar do fluxo já se apresentar constante neste tempo, o volume de permeado ainda é muito pequeno, por isso a microfiltração se estendeu por mais 50 minutos.

Com os resultados da Tabela 2 e da Figura 4, observa-se que a membrana com porosidade de $0,22 \mu \mathrm{m}$ se mostrou mais eficiente no processo de clarificação e concentração do chá verde, já que houve uma redução de $20,95 \%$ de sólidos solúveis e uma concentração de $80,70 \%$ das catequinas totais no permeado. Mesmo este permeado apresentando a menor concentração de catequinas, ele ainda se mostra mais interessante, pois garante uma solução com menor quantidade de impurezas. A membrana que apresentou a maior concentração de catequinas no permeado foi a de porosidade $0,8 \mu \mathrm{m}(1025,71 \mathrm{mg} / \mathrm{L})$, porém ela não reteve praticamente nada dos sólidos presentes na solução inicial, apresentando uma redução de apenas $0,8 \%$. Ela não se mostrou eficiente, por não clarificar o permeado.

\section{CONCLUSÃO}

Baseado nos resultados apresentados neste artigo, concluímos que a temperatura ótima de extração das catequinas do chá verde é $75^{\circ} \mathrm{C}$. Nesta temperatura foi obtida a maior concentração de catequinas que foi de $1612,80 \mathrm{mg} / \mathrm{L}$. Temperaturas superiores não devem ser utilizadas uma vez que os compostos bioativos de interesse começam a ser decompostos. O fluxo do permeado para as três membranas passa a ser constante após 10 minutos de operação. Esta é uma característica particular de filtrações que ocorrem em batelada, ou seja, assim que a solução é submetida a uma pressão, a torta se forma quase que instantaneamente e por isso o fluxo estabiliza rapidamente. $\mathrm{O}$ processo de filtração se estendeu por 60 minutos, para obter um volume de permeado suficiente para análise.

Para o processo de separação com membrana, a membrana que apresentou um resultado mais satisfatório foi a de porosidade $0,22 \mu \mathrm{m}$, já que o permeado encontrou-se rico em catequinas $(80,70 \%$ das catequinas iniciais), e apresentou uma redução dos sólidos solúveis de $20,95 \%$.

\section{REFERÊNCIAS}

BARBOSA, I. L. Avaliação de Processos de Separação por Membranas para Geração de Águas de Reúso em um Centro Comercial. 2009. 124p. Dissertação (Mestrado em Tecnologia de Processos Químicos e Bioquímicos) - Universidade Federal do Rio de Janeiro, Rio de Janeiro, 2009.

CARNEIRO, L. C., GOMES, F. S., FURTADO, A. A. L., CABRAL, L. M. C. Esterilização de Suco de Abacaxi por Microfiltração. Embrapa, v.39, p.1-6, 2000.

CHANDINI, S. K., RAO, L. J., SUBRAMANIAN, R. Membrane Clarification of Black Tea Extracts. Food Bioprocess Technology, v. 6, p.1926-1943, 2013.

HABERT, A. C., BORGES, C. P., NOBREGA, R. Processos de Separação por Membranas. Brasil. E-papers. 2006.

JIANG, H., ENGELHARDT, U. H., THRÄNE, C., MAIWALD, B., STARK, J. Determination of Flavonol Glycosides in Green Tea, Oolong Tea And Black Tea by UHPLC Compared to HPLC. Food Chemistry, v.183, p.30-35, 2015. 
KAWAKATSU, T., KOBAYASHI, T., SANO, Y., NAKAJIMA, M. Clarification of Green Tea by Microfiltratio and Ultrafiltration. Bioscience Biotechnology and Biochemistry, v.59, p.1016-1020, 1995.

KUMAR, A., THAKUR, B.K., DE, S. Selective Extraction of (-)Epigallocatechin Gallate from Green Tea Leaves Using TwoStage Infusion Coupled with Membrane Separation. Food Bioprocess Technol, v.5, p.2568-2577, 2012.

LEE, J. E., LEE, B. J., CHUNG, J. O., KIM, H. N., KIM, E. H., JUNG, S. Metabolomic Unveiling of a Diverse Range of Green Tea (Camellia Sinensis) Metabolites Dependent on Geography. Food Chemistry, v.174, p.452-459, 2015.

NAGAO, T., HASE, T., TOKIMITSU, I. A Green Tea Extract High in Catechins Reduces Body Fat and Cardiovascular Risks in Humans. Obesity, v.15, p.1473-1483, 2007

TEREFE, N. S., DELON, A., BUCKOW, R., VERSTEEG C. Blueberry Polyphenol Oxidase: Characterization and the Kinetics of Thermal and High Pressure Activation and Inactivation. Food Chemistry, v.188, p.193200, 2015.

\section{AGRADECIMENTOS}

Os autores agradecem o apoio financeiro da CAPES, CNPQ e FAPEMIG. 